\title{
Specifics of sea graduates' professional training in Russia
}

\author{
Irina Sevastyanova ${ }^{1, *}$, Svetlana Motornaya $^{1}$, and Alexey Korepanov ${ }^{1}$ \\ ${ }^{1}$ Sevastopol State University, 299053, 33 Universitetskaya str., Sevastopol, Russia
}

\begin{abstract}
The work of the seaman is characterized by isolation from the land, high probability of emergency, implementation of professional duties in extreme conditions. Life of the crew and safety of the vessel depend on the accuracy of seamen's actions that's why the need of improving seamen's professional training is brought to light. The carried-out analysis of scientific literature, sea, and educational normative documents has defined the specifics of seamen's professional activity, which includes knowledge, communication with people, fast decision-making for ensuring buoyancy of the vessel and safety of the crew in extreme conditions. It has been defined that successful activity of the seaman depends on professional knowledge, skills, as well as professional and personal qualities and the created meanings which are set to be shaped in the course of professional training in higher educational institution. The experimental research with a view to defining the relation of sea profile graduates to the world and future professional activity is carried out. The following personal qualities necessary for the seamen's successful professional activity are delineated: ability to system thinking, leadership skills, communicative culture, multilingualism, morality, creativity, psychological stability during the work in the conditions of uncertainty, aspiration to cooperation. The need of improving seamen's training in the educational process of higher educational institution is revealed. The new paradigm of higher education that focuses on the realization of internal reserves of the personality is represented: the formation of personal qualities along with knowledge, skills which constitute professional conceptosphere of sea graduates. It is recommended to reflect the shaping of personal qualities and meanings in the educational standard and programs of sea graduates' professional training.
\end{abstract}

\section{Introduction}

Today, new methods and ways of modernizing the system of the higher education are evolving. One of the key vectors of development of the higher education proves to be the sea vector. Development and economic growth of the states depend not only on the level of technologies and industry advance but also on the level of the development of sea water areas which are still insufficiently studied. So, in quickly changing world the accent shifts

\footnotetext{
* Corresponding author: irsevastyanova@gmail.com
} 
onto the development of sea infrastructure, and mastering the professional training of sea specialists in this field of activity. The higher school is entitled to provide training of sea specialists who are able to competently and effectively carry out their duties. But it is excruciatingly important to study and reconsider the requirements to competence of the seaman which are mentioned in the professional standard, and to consider the features of seamen's practical activity.

The shaping of personal qualities, professional knowledge, skills gives a boost to the development of sea direction at the level when the future graduate of this profile creatively thinks in any conditions and under any circumstances. The practical activities of sea specialists are connected with schemes, schedules, signals which contribute to shaping the navigators' structural thinking, finding reflection in concepts. The professional duties of navigators are the following: reading sea charts and their analysis, astronomical determination of the vessel's place, graphic and analytical designation of the ship's route, designation of the vessel's route on a gyrocompass and a magnetic compass, definition of the ship's position in the visual and acoustic ways, transferring of visual and sound signals for the safety of navigation

On the one hand, there is a question of minimizing language means as one formulated phrase or statement contain the semantic meaning. When there is a threat to security of the vessel, one of the key words can be used. Moreover, professional activity of the navigator relies on the perception of sounds, signals, colors which bring about the psychological reaction and activization of the psychological mechanisms. The sound signals, which are regulated by International Rules of Preventing Collision at Sea, are of great importance while maneuvering. Besides, navigators must be able to work with different types of charts such as navigational, synoptic, facsimile. While plotting the course, the navigator deals with schemes, signs on graphic and electronic charts. The next key moment in ensuring the seaworthiness of the vessel and safety of life at the sea is supposed to be the ability to decipher the signs, defining navigation danger. To perform successfully professional activity, it is essential to shape the professional conceptosphere which enables the development of the personality.

On the other hand, professional activity of the navigator is carried out in special conditions because of isolation from the land. It is connected with night shifts, physical and information activity, danger and risk, emergency situations which require an immediate assessment and decision-making, and also assumes the formation of special personal qualities.

The navigators' professional conceptosphere is aimed at shaping personal qualities and also professional meanings along with knowledge and skills. Therefore, the specifics of navigators' professional activity make us rethink the principles of training of sea profile graduates in the conditions of higher educational institution.

\section{Conceptual framework and aims of the study}

The requirements to the level of seamen's competence are pointed out in the following international documents: The sea doctrine of the Russian Federation", the law "About state control of sea activity of the Russian Federation", the Federal target program "World Ocean" for 2016 - 2031, "The International convention on preparation and certification of seamen and execution of watch of 1978 with additions of 1995", "The Regulation on certification of crew members of sea vessels with additions of 2015", the International code (ISM code), the Convention SOLAS-74/78, International Regulations for Preventing Collisions at Sea, the Resolution of IMO A.918 (22), the Resolution of IMO A.1070 (28), etc. Moreover, a number of projects on the development of sea environment are being 
implemented by the countries of the European Union among which: AtlantOS, SOPHIE, Sea Change.

A. N. Yuminov, Sergey S. Moyseenko have considered the questions of an increase in the efficiency of continuous training of sea specialists; Vladimir A. Chkoniya, Vladimir.N. Dulin, Yuriy Velichko, etc. have studied the technical aspect of sea specialists' training in higher educational institutions; The importance of cross-cultural and professional communication is noted in the scientific researches of such scientists as Helene V. Tsibulskaya, Tatyana V. Polyakova, Veronika N. Zykova, Vera F. Tenishcheva, Valentina. S. Chernyavskaya, Lyudmila G. Stupina, etc. have revealed importance of cross-cultural and professional communication of sea experts. However, despite a significant amount of scientific works in the field of sea education, the specifics of professional training of the seaman-navigator has not been revealed properly.

The objective of our research is to reveal the specifics of seamen's professional training. For reaching the objective, it is necessary to fulfil the following tasks: to carry out the analysis of the international and national normative documents in sea sphere; to carry out the theoretical analysis of scientific literature on a problem of sea profile specialists' training; to delineate the personal qualities necessary for the modern sea specialist in his professional activity.

\section{Specifics of sea graduates' professional training}

\subsection{Theoretical research}

The features and specifics of sea direction of the Russian Federation are caused by the process of integration into the world sea education. The features of sea education depend on the specifics of professional activity of sea specialist. It is essential to highlight that people with various professional standards and different mentality are involved in the working process.

The specifics of seamen's work consists in carrying out activity within the international environment but not within a certain state. As a matter of fact, the main modern requirements to the profession of the seaman are listed in the international normative documents.

The features of sea education are caused by the specifics of professional activity of the sea specialist both during the work on the vessel and cargo operations. It is essential to highlight that people with various professional standards and different mentality are involved in the working process.

According to the Resolution of IMO A.918 (22) [1], the purpose of using standard phrases of IMO in communication lies in providing assistance in safety of navigation and control of the vessel. As one of the fundamental factors determining safety of navigation proves to be the standardization of the language used in communication when being at the port, in harbor as well as during the communication in foreign crews. In other words, standard phrases are considered to be the language of safety with a view to exchanging significant information between sea profile specialists all over the world.

We are bound to give an example of the signals or codes which navigators use in their professional activity: A (Alfa.-) - I have a diver down; keep well clear at low speed; *B (Bravo, - ...) - I am taking in, or discharging, or carrying dangerous cargo; C (Charlie,-.-..) - Affirmative "yes"; *D (Delta,-.) - Keep well clear of me, I am manoeuvring with difficulty; *E (Echo, .) - I am altering my course to starboard; F (Foxtrot, .-.) - I am disabled; communicate with me; G (Golf,-.) - I require a pilot; Q (Quebec,-.-) - My vessel is wealthy and request free pratique; $* \mathrm{~S}(\mathrm{Sierra}, \ldots)-\mathrm{I}$ am operating astern propulsion, etc. 
When there is a threat to the security of the vessel, in the message one key word which contains a certain semantic meaning can be used: MAYDAY (disaster) - the vessel is under threat, the immediate help, PAN (urgency) - the message which is connected with safety of the vessel or safety of the person, SECURITE (safety) - the message about safety of navigation or a meteorological situation is necessary.

Besides, if the vessel appears in an emergency and needs the assistance, then the following signals can be used: a smoke signal which emits orange color, a signal based on a combination of sounds ...---... (SOS), according to the Morse Code, signals of emergency radio buoys. Thus, professional activity of the navigator relies on the perception of sounds, signals, colors which cause psychological reaction and activization of psychological mechanisms.

The use of sound signals while maneuvering are regulated by International Regulations for Preventing Collisions at Sea. When two vessels disperse in narrow pass, one of vessels gives two long sounds - "I intend to overtake you on the starboard side", two long and two short sounds - "I intend to overtake you on the port side". In case if one vessel fails to understand the actions of other vessel, then five short sound signals or five short light gleams are given. If the vessel approaches a bend, and other vessels are out of sight because of obstacles, then it is to give one long sound.

Moreover, while plotting the course, the navigator deals with schemes, signs on graphic and electronic charts. Weather and facsimile charts serve for forecasting of weather conditions. So, storm warnings, reviews, forecasts "are transferred by the full text in language of the country, and in English. If for any reasons English can't be used, then warning are passed on by the digital meteorological FM 61D MAFOR code". In case of dangerous weather conditions "reports ... are transferred in national and English languages or by means of the international, digital, meteorological codes". However, if any information on the dangerous issue fails to be transferred, then "these characteristics are added by words to the text of the telegram coded by the corresponding code".

While vessels are passing by navigational dangers, there are warning signs of system A (red on the left) and systems B (red on the right). This system includes five types of signs: lateral signs (Lateral Marks), cardinal signs (Cardinal Marks), signs protecting separate dangers (Isolated Danger Marks), axial signs or pure signs (Save Water Marks), signs of a special purpose (Special Marks). Each type of signs provides a safe pass of the vessel on maritime routes.

It should be noted that the European Union realizes a number of projects such as AtlantOS, SOPHIE, Sea Change, which are aimed at the development of the sea technologies, providing the future development of sea environment, literacy and marine culture.

Today, in real practice there are also requirements which are imposed by national shipping companies. The leaders in the sea sphere prove to be German and Greek shipping companies. So, the German company "Briese Schiffahrt" makes a number of requirements which include not only professional knowledge, skills but also personal characteristics of the seaman which define successful professional activity in the working conditions at the sea, namely: abilities to carry out professional duties, leadership skills, ability to system thinking, multiculturalism, professional and interpersonal communication, psychological stability, aspiration to cooperation, discipline, responsibility.

An effective professional training of sea profile specialists must be carried out taking into account the requirements of professional and educational standards. The following documents belong to the professional standard: "The sea doctrine of the Russian Federation", the law "About state control of sea activity of the Russian Federation", the Federal target program "World Ocean" for 2016 - 2031, "The International convention on preparation and certification of seamen and execution of watch of 1978 with additions of 
1995", "The Regulation on certification of crew members of sea vessels with additions of 2015", the International code (ISM code), the Convention SOLAS-74/78, International Regulations for Preventing Collisions at Sea, the Resolution of IMO A.918 (22), the Resolution of IMO A.1070 (28), etc.

A set of requirements to profession of the seaman are mentioned in the sea documents of the Russian Federation. "The sea doctrine of the Russian Federation" [2] contains the purposes and tasks which are directed to realization of sea vector of the state, development of educational structure and marine science. In the document the need of "mobilizing individual readiness of ship's crew", "complex improvement of professional and psychological selection and an educational system by all types of sea activity" is emphasized. The main mission of the development of sea branch proves to be "development of educational structure and marine science with the emphasis on all types of sea activity". Thus, the change of system of training of sea profile specialists is of great importance. In the Federal law "About state control of sea activity of the Russian Federation" [3], the importance of "preservation and improvement of educational process and upbringing of youth" is accentuated. In the Federal target program "World Ocean" for 2016 - 2031 [4] the problem of safety at sea is considered: "the boost of economic activity in the ocean and on the coast requires effective way of providing its safety". That's why professional training of sea profile specialists should be realized, paying attention to professional and personal qualities which ensure successful seamen's professional activity.

According to the Main educational program of the higher education of specialty 26.05.05 "Navigation", the purpose of professional training is set to be "development of students' personal qualities, and also shaping of cultural (universal) and professional competences according to requirements of Federal State Educational Standard of Higher Education on this specialty" [5, p. 6].

Along with the Russian and International normative documents, in the Russian educational system there are also program requirements to professional training of sea specialists. In the Article 69 of the Law "About Education in the Russian Federation" [6], the importance of "satisfaction of the personality's needs for intellectual, cultural and moral development, improvement of educational system, scientific and pedagogical qualification" is emphasized. As a matter of fact, professional training of the future seamen must be based on an individual reserve of the personality.

In the National doctrine of education in the Russian Federation [7], the need of individualization of an educational system which is possible only on condition of shaping of the harmonious personality capable of thinking creatively, and performing effectively professional duties in the conditions of the increased risk is noted. Moreover, it is necessary to provide "variety of educational institutions and the variability of the educational programs, providing individualization of education, personally-oriented education".

The analysis of Federal State Educational Standard of Higher Education of the specialty 26.05.05 "Navigation" (level - specialist program) allowed us to determine the main field of seamen's professional activity: operational and technological; organizational and administrative; production and technological; design; research; scientific and pedagogical. Cultural competences and professional competences which are formed thanks to the study of professional, humanitarian, social and economic subjects are designated in Federal State Educational Standard of Higher Education [8]. As a result, we have outlined the competences which require a more detailed consideration.

It is worth mentioning that Federal State Educational Standard of Higher Education includes not only knowledge, skills, but also personal qualities which define the competences of the Educational Standard. In the Main educational program on the specialty "Navigation" it is marked that "results of mastering Federal State Educational Standard of Higher Education are defined by the competences acquired by the graduate, i.e. his ability 
to apply knowledge, abilities and personal qualities according to the tasks of professional activity" [8, p. 12].

Thus, we have selected the following competences from the Educational Standard [8]:

- "Ability to represent modern picture of the world on the basis of the integral system of natural-scientific and mathematical knowledge, to orient yourself in values, life and culture";

- "Understanding of the essence and $\mathrm{t}$ social significance of the future profession, manifestation of steady interest, high work motivation";

- "Ability to social interaction on the basis of accepted moral and legal norms, showing respect for historical heritage and cultural customs, tolerance for other nationality and culture in the conditions of multinational crews, compliance with the standards of professional and corporate ethics, ability to create cooperation in the crew, knowledge of self-regulation techniques and methods of constructive solving of conflict situations in different conditions";

- "Ability and readiness for the active communication in productive sector and social sphere, freely using Russian and foreign (English) languages as the means of business communication, public speaking skills and scientific speech";

- "Ability and readiness for adapting to new situations, overestimation of the accumulated personal and others experience, the analysis and assessment of the opportunities, independent self-education in new conditions of production with ability of setting priorities to achieve the goal in reasonable time";

- "Ability to provide appropriate visual and acoustical observation and use all available technical means for preventing situations of collisions";

- "Ability to work in emergency situations according to the international and national requirements, to make necessary assessment of risks";

- "Readiness to keep necessary operational documentation in English";

- "Ability and readiness to organize team work with national, religious and welfare diversity, to distribute powers and delegate responsibility";

- "Ability and readiness to organize team work in difficult and emergency conditions, to choose, to justify, to accept and perform an administrative decisions within acceptable risk, ability to assess conditions and consequences of the made organizational and administrative decisions";

- "Knowledge of the international standard language in the volume necessary for performance of the functional duties and the organization of international crew management";

- "Ability to set the purposes of the project (program), to find the solution of tasks, criteria and rates of the goal achievement, to interrelate them, to reveal priorities of the tasks solution taking into consideration the system of national and international requirements, moral aspects of professional activity".

The Federal State Educational Standard of Higher Education with additions of 2017 consists of professional, cultural and universal competences classified in groups. Universal competences are divided into some groups such as systematic thinking, leadership, team work, realization of projects, communication, multicultural interaction, safety of shipping. But these competences, on the one hand, do not consider and include the specific details of navigator's professional activity as the navigator deals with signs, schemes, signals, sounds and performs his duties in extreme conditions which influence him, on the other hand, they are not reflected in the educational program and realized in the educational process. The point is that these shortcomings are to be eliminated in the educational process.

Evgeniy A. Klimov [9] formulates the main demands to representatives of a specific professional activity. Following Evgeniy A. Klimov's classification, sea specialists, in particular navigators, belong to the category of "person-system" since their work is 
connected with schedules, schemes, sounds and sign systems. It acknowledges the idea of the necessity of forming concepts.

Shaping interpersonal relations, forming outlook and cultural values of youth turns out to be the mission of the higher education. An important condition of shaping professional picture of the world of seamen is overcoming cultural and linguistic barriers. The use of a foreign language is caused by both professional purposes, and in the sphere of polycultural communication. Veronika N. Zykova delineates that "the navigator should be able correctly and quickly make decisions in difficult professional situations, perform foreign-language communication at the high level as life of all crew and the vessel often depends on him" $[10$, p. 10]. However, it is impossible without possessing professional knowledge since "professional language training can start only on the basis of professional knowledge on special disciplines" [10, p. 98].

In its turn, Helene V. Tsibulskaya accentuates the importance of professional and sociocultural communication, but also about the leadership skills of the sea specialist. Helene V. Tsibulskaya highlights that the navigator should have qualities of the head since the graduate embarks on working in the capacity of the third officer and he is in charge of all crew, including extreme conditions [11, p. 9].

In her research, the scientist Lyudmila G. Stupina emphasizes that "training of future sea specialists in higher education institution is aimed, first of all, as acquaintance of professional knowledge, and communicative competence is not always realized by future sea specialists as an important condition of their effective professional activity" [12, p. 76].

The requirements of the leading shipping companies and the crew agencies include the Certificate of competency requiring foreign language skills, high level of communicative skills, abilities to agree and answer about previous work experience in the mixed crews. Thus, foreign-language professional and communicative competence, according to the author, is a backbone factor of successful professional activity of the sea specialist. Globalization processes are connected with forming of the polyculture personality that is ready to "cross-cultural interaction not only at the level of the use of word meanings and phrases, but also at the level of meanings taking into account cultural features, values and mental abilities of a certain professional community, which results in forming sphere of concepts of the specialist" [13, p. 36].

The differences between requirements to a profession of the seaman and the real existing preparation demonstrate that sea profile specialist must possess both professional competences, and professional and personal qualities [14, 15, 16, 17].

As a result of the analysis of normative documents and scientific literature we have marked out the following personal qualities necessary for the seaman: ability to system thinking, leadership skills, communicative culture, multilingualism, morality, creativity, psychological stability during the work in the conditions of uncertainty, aspiration to cooperation. Thus, we observe forming of the new concept of professional education, which is based on the ideas of development and self-development of the personality. The new paradigm of professional education, including the higher education, is oriented towards realization of the internal potential of the personality.

The personal qualities must be reflected in the educational standard and become a basis for programs of sea specialists' training. It also defines the specifics of navigators' training.

\subsection{From theory to practice}

The sea specialist must perceive signs, signals, symbols and decode the obtained information, react quickly to various situations, make operational decisions, interact, and carry out communication at all levels - all this, undoubtedly, depends on the level of shaping of seamen's professional picture of the world. In other words, the seamen's 
professional picture of the world represents a set of the implications and professional and personal meanings. The shaping of professional and personal meanings defines the perception of a professional sphere. The aim of diagnosing this category is the following: the seaman who is carrying out the professional activity in extreme conditions must possess the system of professional and personal meanings as well as professional knowledge. This process is inseparably linked with the level of shaping of the concepts which are the constituent components of sea specialists' professional sphere of concepts.

The search of diagnostic tools with a view to determining the set parameter became a fundamental step in our research. For this purpose we have chosen a rating scale "Semantic differential" by Ch. Osgood. This scale has been developed with a view to identifying semantic sphere of the personality that allows to carry out the quantitative and qualitative analysis of professional and personal meanings. While evaluating, the system of personal meanings is brought to light at the level of consciousness being a logical antithesis. Evaluating the set of parameters, the respondent has certain incentives. Each word has both denotation and connotation. The respondent independently perceives and estimates each metaphorical scale which doesn't contain the direct characteristics. Thus, this approach helps to define ability to perceive information being coded.

In this research, we have set the objective to experimentally approve one of three factors of scaling, the factor called "assessment". It helps us to determine the ability of sea specialists to perceive the information in the form of signs, symbols, schemes, sounds. Our research has been realized at Sevastopol State University. One hundred seventy six firstand second-year students of Navigational department have participated in a research. So, bipolar scales of the adjectives containing bipolar meanings have been suggested. The following couples of metaphors divided into two columns have been suggested: sour-sweet, rough-gentle, dark-light, stale-fresh. The evaluation has been carried out by means of the following points: 1 or -1 - quality in insignificant degree, 2 or -2 - quality in average degree, 3 or -3 - quality in strong degree. The evaluation has been carried out on the basis of the factorial analysis, i.e. bipolar couples of adjectives have been selected and referred to a factor "assessment" (relation). The interval of points varied from -3 to 0 and from 0 to +3 .

As a result of mathematical data processing, the average square deviation which is an indicator of dispersal of values about average value $\mathrm{X}$ has been received. So, navigators have the $X$ relation to the world around $-0,90,6$ relation $-1,25$, i.e. $41,7 \%$. The received results show that the indicator "relation" of future seamen-navigators isn't too high, but is positive. It indicates the existence of communication between respondents and an object of the research. Thus, we can allege that the world exerts an influence on students, forming their outlook and attracting interest.

For comparing the received indicators, the experiment on the specialty "Physics" has been also made. 25 students of 1 and 2 courses have participated in an experiment. As a result the following indicators have been received: $X$ the relation - 0, 24, 6 relation - 2,17. The indicator is negative, so it outlines negative attitude of the respondents physicists to an object of the research. It is possible to highlight that such result reflects a lack of internal harmony, an unstable mental state. The world is the main cause enabling fear of the unknown. The students-physicists feel rather close connection with the world, but they have negative relation to it. Possibly, it is influenced by the fact that the world around is a subject of studying and keen interest for the respondents. There is some with dread before Filled, caused understand her scales a variety.

The comparison of the received results of the experimental data of students of specialties "Navigation" and "Physics" demonstrates that future navigators have the level of perception of the world and professional activity which is higher than future physicists have. The professional activity of seamen, which is carried out in the sea, is a fundamental factor when determining the relation to the world around and professional activity since the 
received indicators are higher. However, it amounts only to $41,7 \%$, and real practice has shown that for the navigator it is important to perceive the professional sphere which is expressed in signs, sounds, terms and, therefore, demands the high level of perception and knowledge of the surrounding reality. Therefore, the formation of the world picture of the seaman, professional conceptosphere which includes the features of sea activity is important. So, in the educational process the introduction of the new program of professional training, which will consider specifics of seamen's activity for the purpose of increasing the efficiency and level of performance of professional activity, is necessary.

\section{Conclusion}

The conducted analysis of scientific literature, sea and educational normative documents has shown the need of deepening the theoretical study of the features of educational process of sea specialties. Training for a number of the specialties providing the sea direction is to become the basis of development of the system of continuous education. The sea profile specialists should possess both professional and necessary personal qualities and meanings which ensure their successful professional activity. The following personal qualities necessary for the seamen's professional activity have been defined: ability to system thinking, leadership skills, communicative culture, multilingualism, morality, creativity, psychological stability during the work in the conditions of uncertainty, aspiration to cooperation.

By means of experimental research based on the method of "The semantic differential" by Charlz Osgood, the relation to the world has been investigated. It has been revealed that this indicator is positive and higher than the future experts in the field of natural sciences have; however, it amounts only to $41,7 \%$ of the necessary maximum. Therefore, the need of the formation of personal meanings on the basis of concepts has been confirmed. The specifics of preparation consists in creating the ability to system thinking, developing leadership skills, communicative culture, multilingualism, morality, creativity, psychological stability during the work in the conditions of uncertainty, aspiration to cooperation. All in all, the educational program of professional training is to be made taking into account the specifics of professional activity of the seaman. A problem of a higher educational institution consists in reforming of system of professional training of sea specialists, at which requirements of professional and educational standards will coincide.

\section{References}

1. Standard phrases of IMO for communication at sea; the Resolution of IMO A.918 (22) (http://www.http://saillife.ru/wp-content/uploads/2015/04/Frazi.pdf 2016)

2. The Sea doctrine of the Russian Federation (http://www.static.kremlin.ru/media/ events/files/ru/uAFi5nvux2twaqjftS5yrIZUVTJan77L.pdf, 2015)

3. The Draft federal law "About public administration by sea activity of the Russian Federation” (http://www.fondrosflot.ru/?q=collegium/proekt-federalnogo-zakona-ogosudarstvennom-upravlenii-morskoy-deyatelnostyu-rossiyskoy)

4. The concept of the federal target program "The World Ocean" on 2016-2031 (http://www.base.consultant.ru/cons/cgi/online.cgi?req=doc\&base=LAW\&n=181423 \&fld $=134 \& \mathrm{dst}=100010,0 \& \mathrm{rnd}=0.9767031293511363,2015$ )

5. The Main educational program of the higher education for the specialty "Navigation" (Moscow, 2016) 
6. The Federal law "About Education in the Russian Federation" (http://www.http://base.consultant.ru/cons/cgi/online.cgi?req=doc\&base $=$ LAW\&n=20 $1143 \& \mathrm{fld}=134 \& \mathrm{dst}=1000000001,0 \& \mathrm{rnd}=0.5995649339170868,2016$ )

7. The National doctrine of education in the Russian Federation (http://www.voenprav.ru/doc-1329-1.htm, 2016)

8. The Federal state educational standard in "Navigation" (Moscow, 2010)

9. E. Klimov, Psychology of professional self-determination (Moscow, 2004)

10. V. Zykova, The formation of professionally communicative competence of students of navigation departments: 13.00.02 (St. Petersburg, 2002)

11. H. Tsibulskaya, Theory and methodology of professional language education of sea navigators: PhD dis: 13.00.08 (Novosibirsk, 2001)

12. L. Stupina, Forming of foreign-language professional and communicative competence of sea specialists in the educational complex "sea lyceum-sea higher education institution": PhD dis: 13.00 .08 (Kaliningrad, 2012)

13. N. Sukroyeva, Multilingual communication as factor of development of sphere of concepts of future specialist (Moscow, 2011)

14. I. Sevastyanova, M. Sotornaya, Sea profile specialist today: connection of personal qualities with working conditions (http://ucom.ru/doc/ns.2016.01.148.pdf, 2006)

15. I. Sevastyanova, The profession of marine profile specialist: technical and personal aspects (http://ucom.ru/doc/na.2016.01.02.283.pdf, 2016)

16. I. Sevastyanova, The main principles of sea education: materials of the international research and practice conference "New science: from the idea to result" (Surgut, 2016)

17. I. Sevastyanova, Relevance of application of IMO standard phrases (IMO Standard Marine Communication Phrases) in training of sea profile specialists: materials of the international research and practice conference "New science: from the idea to result" (Sterlitamak, 2015) 